\title{
A SHORT HISTORY OF AN EXOTIC CARNIVOROUS PLANTING IN NEW JERSEY, USA
}

\author{
Barry A. Rice - Center for Plant Diversity - University of California - One Shields Avenue • \\ Davis, California 95616•USA•bamrice@ucdavis.edu \\ JIM BocKOwsKI • 7168 N. Pale Moon Tr. • Tucson, Arizona $85743 \bullet$ USA
}

Keywords: field studies: New Jersey, Sarracenia — conservation: non-native species.

More than thirty years ago, a few non-native carnivorous plants were introduced into a prime wetland in New Jersey. We provide a candid description of the events that followed, and the current state of affairs at this site. While it is now widely understood that such introductions of non-native plants into wildland areas are generally unwise, back then this knowledge was not so widespread. This paper is not intended to debate the merits or dangers of introducing non-native plants, nor is it intended as an exercise in laying blame. It is hoped, however, that future botanists encountering this site might find this paper illuminating and clarifying.

The Pine Barrens

For carnivorous plant enthusiasts, southern New Jersey is well known as a hotbed of carnivorous plants. This region of the USA — known as the Pine Barrens - is rich with bogs and other wetlands, and its list of native carnivorous plants excels! The Utricularia list is particularly rich: Utricularia cornuta, U. geminiscapa, U. gibba, U. inflata, U. intermedia, U. juncea, U. macrorhiza, U. minor, $U$. olivacea, U. purpurea, U. radiata, U. resupinata, U. striata, and U. subulata (Rice 2007). Of course, to complete the carnivorous plant list you must include Sarracenia purpurea, Drosera filiformis, D. intermedia, and D. rotundifolia. The Sarracenia purpurea plants are particularly enjoyable to those who like puzzles, since this part of the USA is in the overlap zone between the ranges of S. purpurea subsp. venosa and $S$. purpurea subsp. purpurea. Many times I (BAR) have encountered a pitcher plant in "the Barrens" and was unable to confidently classify it to subspecies. Such plants, exhibiting intermediate characteristics, are often referred to as "New Jersey intergrades." New Jersey is also the only state where the sterile hybrid Drosera $\times$ hybrida has been recorded as native (Brittnacher 2011).

Navigating the Barrens can be a challenge. The region is a maddening maze of intertwining, unnamed roads. Even today, what to the GPS-enabled, GoogleEarth-savvy researcher looks like an easy trip can be revealed on-the-ground as an impossible journey through flooded basins or deep pits filled with treacherous sugar sand. Even well-equipped 4WD vehicles often become mired-a powerful winch can be an invaluable tool!

The Barrens are so formidable, it is no surprise that they are famously haunted by an entity called the Jersey Devil - a monster that seems to have crawled out of the pages of a horror story by H.P. Lovecraft. But for visitors with an interest in the natural world, the Pine Barrens are beautiful, and rapidly find a place in the heart.

\section{8 introduction}

Jim Bockowski (second author) grew up in the New York area, and visited the Pine Barrens repeatedly from 1962 to 2006. By the late 1970s he had identified one area that seemed suitable for 
some plant introduction experiments. His main motivation was not scientific - rather, he needed a place to keep his plants while he was moving from one apartment to another.

The site he selected was in effect a natural impoundment. Numerous small streams and seepages led into the site, but dense growths of Sphagnum clogged the sole outflow. As a consequence, any detached plantlets that might result from his introductions would be prevented from leaving. This provided a degree of isolation he was looking for. The introduction was conducted in 1977, and consisted of small clumps of Sarracenia flava, S. rubra, S. minor, and Dionaea. They all survived their first winter, and on a monitoring trip Bockowski took with Phil Sheridan in August 1978, they were observed to be in good health (Sheridan 1978). Within another 2-3 years, The Dionaea and S. flava perished. For years afterwards, Bockowski visited the site regularly to remove any and all flower buds - no flowers were allowed to produce pollen because he was concerned that his introductions might hybridize with the natives.

Ten years later-1988

In 1988, I (BAR) visited the Pine Barrens. This was to be the first time I would ever see carnivorous plants in the wild, and I prepared for it carefully. Having read Phil Sheridan's 1978 trip summary to the Pine Barrens, I contacted Jim Bockowski. Jim was kind enough to give this very inexperienced enthusiast fine suggestions on places to visit - including his introduction site. At that time, access involved driving along the busy Garden State Parkway, and following an exit to a rest stop situated among the trees between the northbound and southbound lanes of traffic. The next step was

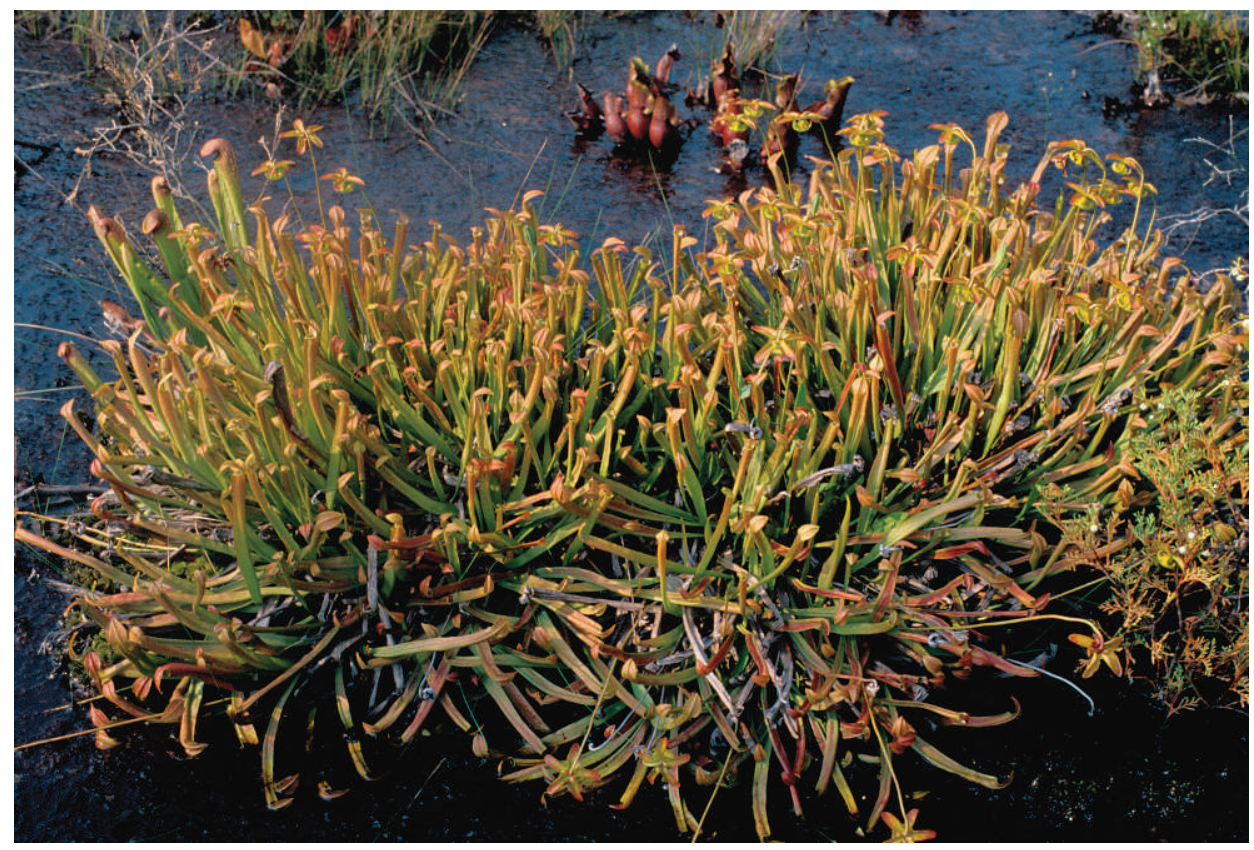

Figure 1: An image from 1988 showing the large clump of Sarracenia rubra and a single plant of $S$. minor (at left). Native $S$. purpurea is visible in the background. Photograph by Barry Rice. 
to wait for a pause in the high-speed southbound traffic, and dart across the lanes on foot - no doubt a questionably legal maneuver. The last leg of the trip consisted of a 1-km walk through a maze of unsigned roads consisting of loose sugar sand and deep puddles that spanned the entire roadway.

The trip was very successful, and I saw the usual ensemble of New Jersey carnivorous plantsSarracenia, Drosera, and Utricularia. Jim's introductions were also flourishing - a few S. minor plants were still there, and the $S$. rubra had grown into a large clump a few meters in diameter (Fig. 1). I noticed numerous spent flowers on the Sarracenia rubra. While all this was interesting to see, I was more excited by the native species that were all around.

Meanwhile, Jim had not been visiting the site as regularly as he would have liked. The site was quite difficult to reach. The situation was made even worse when his only access to the site was blocked. This accounted for the numerous intact flowers I observed. Several years after my trip, he was able to find a new access to the location and was surprised to find that the S. rubra clump had continued to grow, producing hundreds of seed pods. As he emailed me in 2011, "Everywhere I looked in that little bay were seedlings, plants, and hybrids with the purps [S. purpurea]." He even saw a specimen of $S$. rubra $\times$ minor. On this and subsequent trips he began removing and destroying plants at the site. However, this kind of work is very hard (on one trip, assisted by two friends, he removed more than two bushels of plants). Despite frequent eradication trips, there were still plants and hybrids at the site when he retired and moved to Arizona. His last visit to the site was in 2006.

Jim notes another problem at this site-the impact from off-road vehicle enthusiasts. Even a quick study of aerial maps (such as on GoogleEarth) reveals that the area is heavily visited by four wheel drive enthusiasts who enjoy the area for the challenges presented by the mix of sugar sand, puddles, and bogs. (A warning to would-be visitors - some of these enthusiasts do not appreciate outside visitors, and can be threatening or even overtly hostile.)

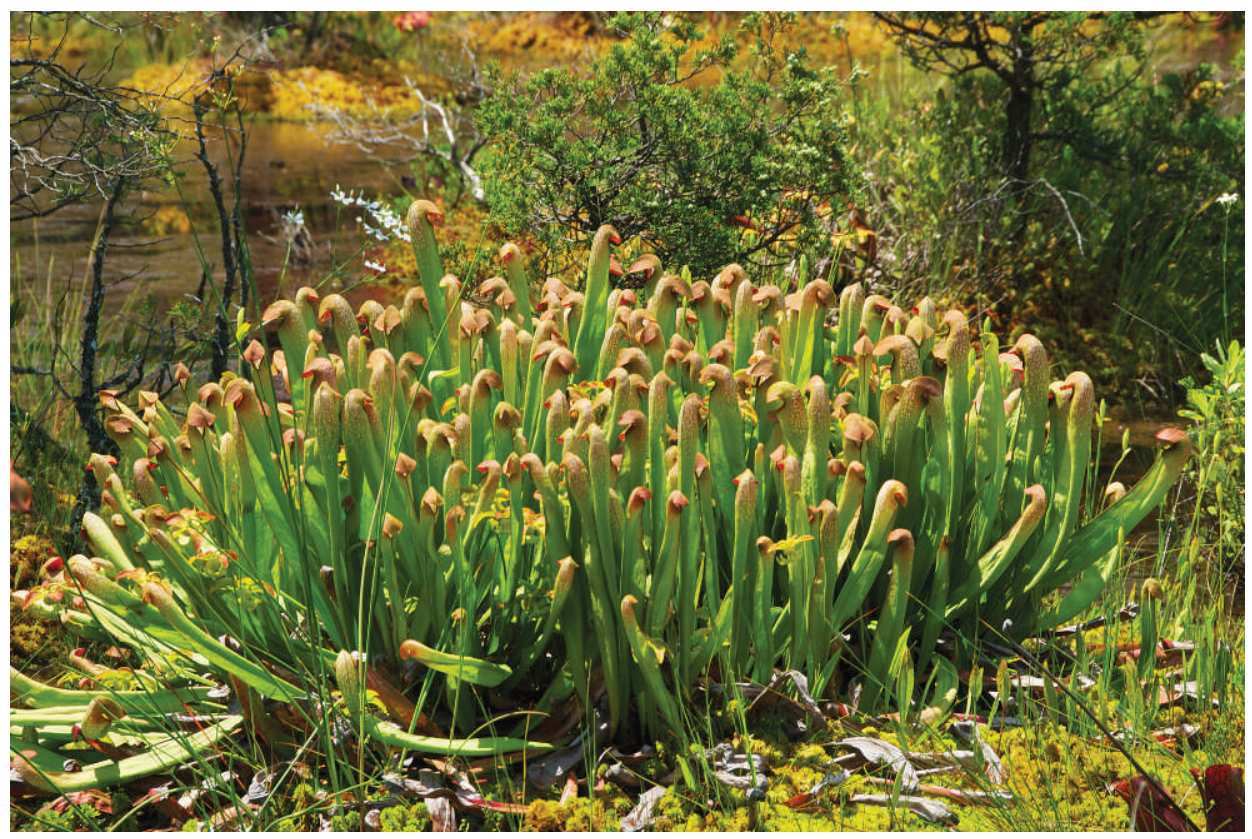

Figure 2: An image from 2010 showing the large clump of flowering Sarracenia minor. Photograph by Jason Ksepka. 


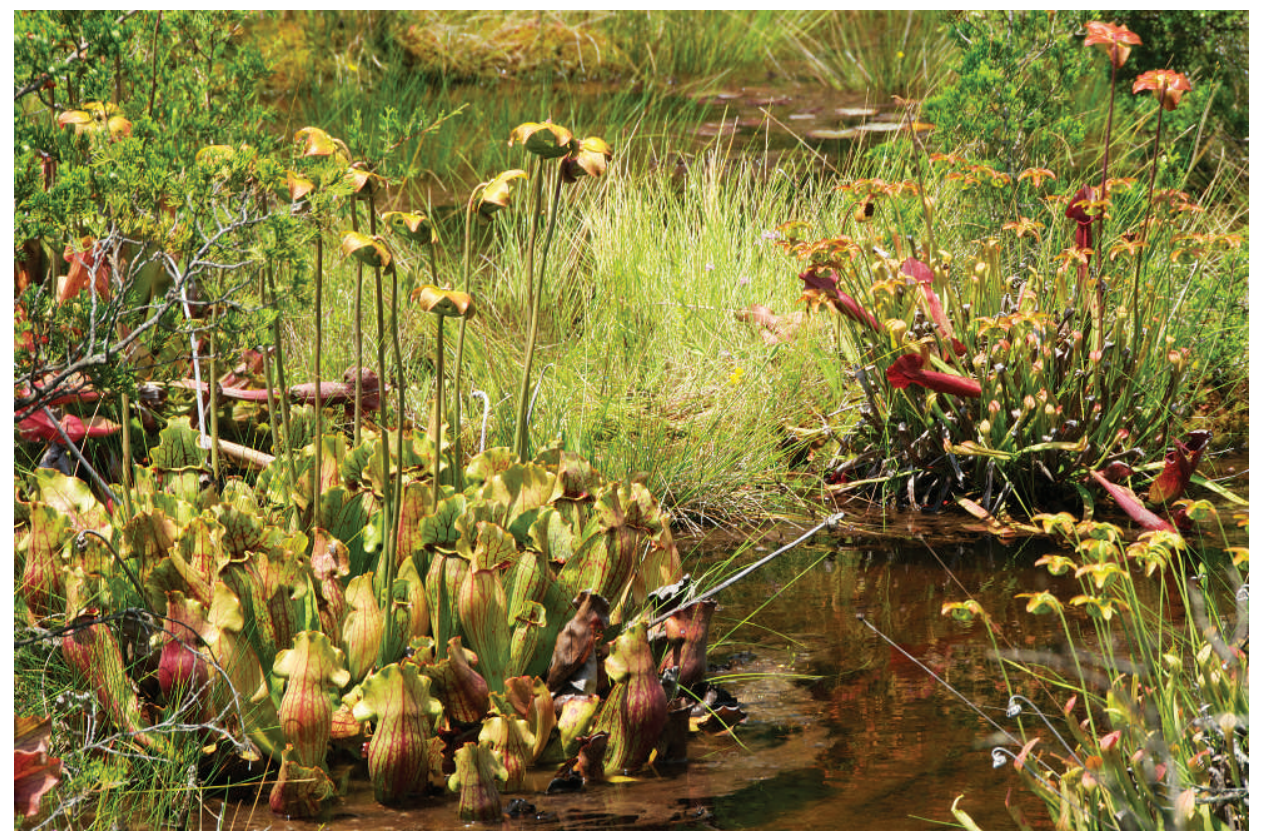

Figure 3: An image from 2010 showing the large clump of Sarracenia purpurea (center-left), clumps of Sarracenia rubra (background-right and foreground-right), and also a few hybrid Sarracenia; all apparently in flower. Photograph by Jason Ksepka.

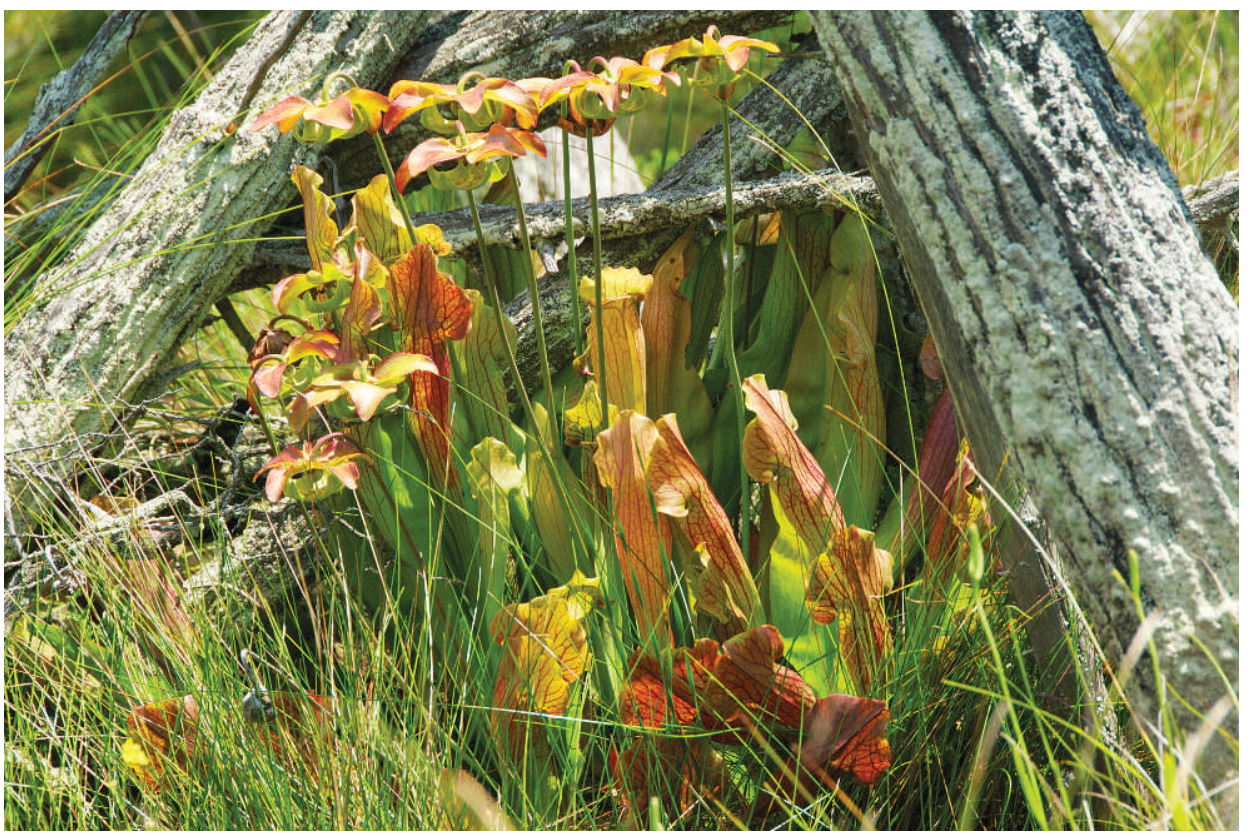

Figure 4: An image from 2010 showing a cross (or backcross) of Sarracenia rubra $\times$ purpurea. Photograph by Jason Ksepka. 
A consequence of the off-road enthusiasts has been a change in the hydrology of the area. Sediments shifted by their activities, and intentional river modifications, have changed how the water filters out of the site. Now, water flows readily out of the site through small channels. Seeds from this hybridization zone - once constrained to stay in the small bay-are now free to float out to the rest of the Pine Barrens.

\section{A 2010-2012 update}

In 2010, Jason Ksepka and Dave Evans visited the site and reported to me what they saw (pers. comm.). They observed a small number of $S$. rubra clumps, a single large clump of $S$. minor (Fig. 2), and several S. rubra $\times$ purpurea hybrids (Figs. 3, 4), all of which had been flowering.

On a subsequent trip in 2012, specimens of both species and the hybrid were collected. I prepared these specimens and submitted them to the herbaria at the University of California, Davis (DAV: Sarracenia minor-BR120604; Sarracenia rubra-BR120606; S. rubra $\times$ purpurea-BR120608) and the Chrysler Herbarium at Rutgers (CHRB: Sarracenia minor-BR120603; Sarracenia rubra-BR120605; S. rubra $\times$ purpurea-BR120607).

Future botanists discovering aberrant Sarracenia in the Pine Barrens should be able to locate these specimens and be forewarned about the genetic contamination that has occurred.

\section{References}

Brittnacher, J. 2011. Drosera $\times$ hybrida rest in peace. Carniv. Pl. Newslett. 40: 112-121.

Rice, B.A. 2007. The Carnivorous Plant FAQ v.11.5, http://www.sarracenia.com/faq.html, accessed 8 March 2013.

Sheridan, P. 1978. New Jersey Pine Barrens. Carniv. P1. Newslett. 7: 107-109.

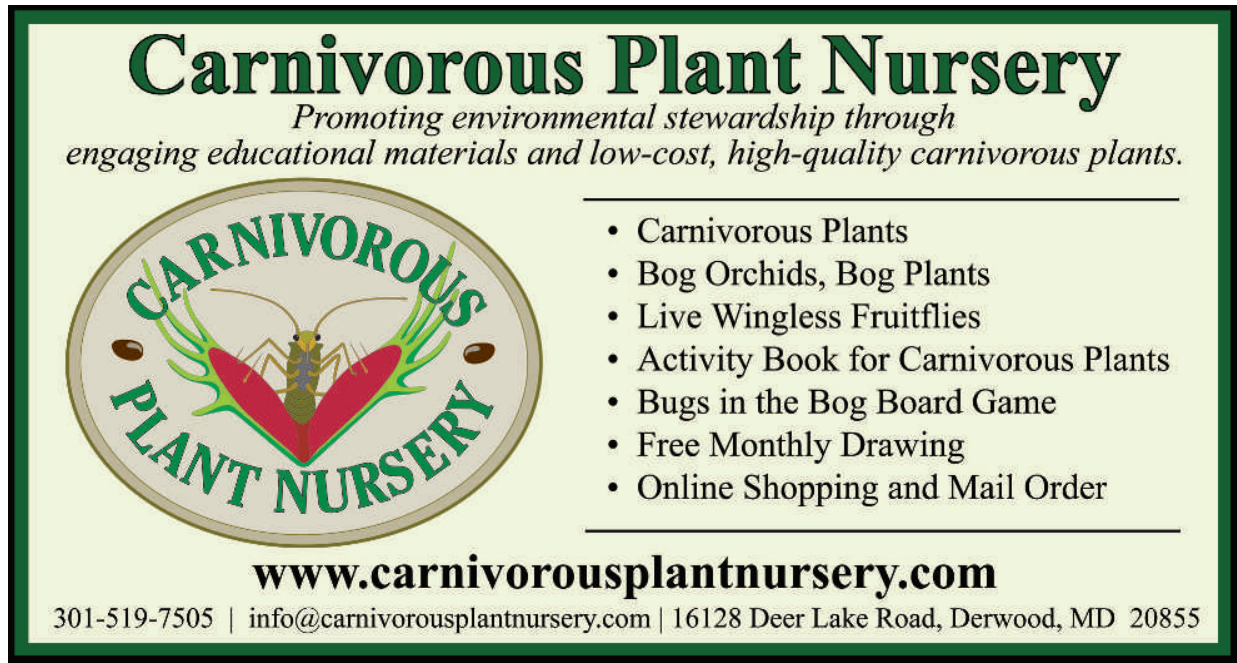

